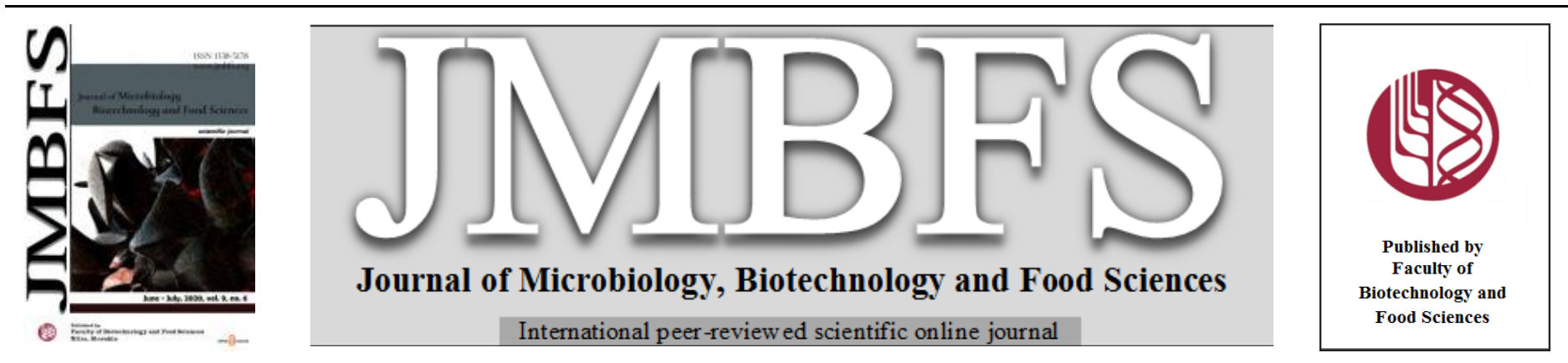

\title{
STUDY ON THE INFLUENCE OF MODIFIED CHITOSAN ON THE PRESERVATION OF TIGER PRAWN PENAEUS MONODON
}

\author{
Rajesh Rajendran ${ }^{1}$, Paari K. A. ${ }^{2}$
}

Address(es):

${ }^{1}$ State Key Laboratory of Catalysis (SKLC), Dalian Institute of Chemical Physics, Dalian, China.

${ }^{2}$ Department of Life science, CHRIST (Deemed to be University), Bangalore, Karnataka, India.

*Corresponding author: paaribiot@gmail.com

doi: $10.15414 /$ jmbfs.2020.9.6.1176-1180

\section{ARTICLE INFO}

Received 11.9. 2018

Revised 17. 2. 2020

Accepted 18. 2. 2020

Published 1. 6. 2020

Regular article

OPEN $\partial_{\text {ACCESS }}$

\section{INTRODUCTION}

Foods products from sea are generally perishable that spoil sooner than other foods. Mounting alertness with reference to the safety of sea food commodities have recently led to copious developments in the field of fish preservation. Storage and processing of seafood products are constrained mainly due to the problems related to the progress of lipid oxidation and off-flavours associated rancidity (Ali et al., 2019). In order to evade the usage of synthetic preservatives, natural substances that carry a 'green' image for preservation of sea food are now being developed in various studies. Chitosan, an amino polysaccharide constituting of glucosamine and $\mathrm{N}$-acetyl glucosamine, has been used widely in food processing, medicine and biotechnology fields (Majeti and Ravi, 2000; Harish Prashanth and Tharanathan, 2007). In the recent past, chitosan becomes an appealing molecule due to its antibacterial, film forming property, antioxidative and biodegradable ability (Fan et al., 2009; Song et al., 2018; Kim and Thomas, 2007; Rhoades and Roller, 2007). Wide spectrum of antimicrobial activity for chitosan was reported against human pathogenic microorganisms (Chen et al., 2010; Raafat and Sahl, 2009). Although a lot of studies have published the antimicrobial nature of this under used polymer, the precise mechanism for its antimicrobial activity remains vague. Fang et al. (2010) stated that the antimicrobial nature of chitosan is caused due to the distraction of the cell membrane of food borne pathogens. Shelf life of fishery products was extended by inhibiting the growth of Pseudomonas and Shewanella by the addition of chitosan (Cao et al., 2009). Radiation is now considered as a handy tool for modification of chitosan for enhancement of their biological activity (Feng et al., 2008). Irradiation was effective in enhancing the antimicrobial action of chitosan against Escherichia coli (Kume et al., 2002). However, a research carried out by Lopez-Caballero et al. (2005) demonstrated negative influence on microbial growth in the presence of powdered chitosan. Investigations on the radiation effects of chitosan showed pronounced increase of antimicrobial and antioxidant activity (Czechowska-Biskup et al., 2005; Park et al., 2004). Enhancement of antioxidant activity of chitosan by gamma irradiation at three different doses was stated by Feng et al. (2008). Suitability of irradiated chitosan in inhibiting oxidative rancidity in meat sample has been reported (Kanatt et al., 2004). Among the diverse modifications that are practicable, blending of synthetic polymer is also a handy mode where the properties of chitosan are personalized and a novel flexible material was developed (Suyatma et al., 2004; Pourjavadi et al., 2003; Mahdavinia et al., 2004; Don et al., 2002). PMMA was blended with chitosan for usage in various biomedical applications (Radhakumary et al., 2005). El-Tahlawy et al. (2006) investigated the changes in the properties of chitosan grafted by methyl acrylate and found that the grafted copolymer was having enhanced antiviral property compared to the unmodified chitosan. Synergistic consequence of chitosan covalently tagged with antimicrobials have been described (Song et al., 2002; Chen et al., 1996). In this study, the antioxidant and antimicrobial activity of chitosan was enhanced using irradiation. The effect of modified chitosan derivatives were analysed during the preservation of Penaeus monodon.

\section{MATERIALS AND METHODS}

Chitosan was irradiated at doses of 5 and $10 \mathrm{kGy}$ in the Gamma chamber facility available with the CIF, Pondicherry University. Cobalt 60 was the irradiation source. Irradiated chitosan was prepared following the protocol of Kannat et al. (2004). Treatment groups for Penaeus monodon preservation were divided as: control (without chitosan treatment): $5 \mathrm{kGy}$ irradiated chitosan treated group: 10kGy irradiated chitosan treated group: Blended chitosan treated group. Penaeus monodon was purchased from the local retail market. Immediately after purchase they were taken back to lab under sterile conditions.

Synthesis of poly (methyl acrylate) polymer grafted chitosan (Chitosan-gPMMA-Scheme- 1)

A $2 \mathrm{~g}$ of $2 \% \mathrm{w} / \mathrm{v}$ chitosan solution was prepared in $250 \mathrm{ml}$ of $1 \%$ aqueous acetic acid. The reaction was carried out at $70{ }^{\circ} \mathrm{C}$ in nitrogen atmosphere. $0.1 \mathrm{M}$ Ceric Ammonium Nitrate in $10 \mathrm{ml}$ of $1 \mathrm{~N}$ nitric acid was then added. 4g MMA was added drop wise with continuous stirring. Sodium hydroxide solution was used to precipitate the product by continuous stirring for four hours and washed with distilled water several times. The homopolymer was extracted in a soxhelet from the grafted product using acetone as solvent. The percentage of grafting was calculated from Thermo gravimetric analysis (TGA)

\section{Characterization}

FT-IR spectra of chitosan and its graft was recorded in the range $4000-500 \mathrm{~cm}^{-1}$ using Nicolet Nexus 470 spectrometer. Chitosan and its graft copolymer was characterized using X-ray diffraction (XRD) and Scanning electron micrograph (SEM). The degradation process and thermal stability of chitosan and its graft copolymer was also analysed. 
Scheme of the graft

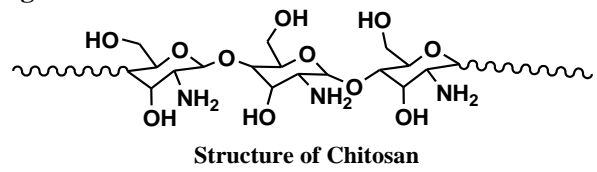

Structure of Chitosan<smiles>[CH2][Y]([CH2])(C)C=CC(=O)OC</smiles>

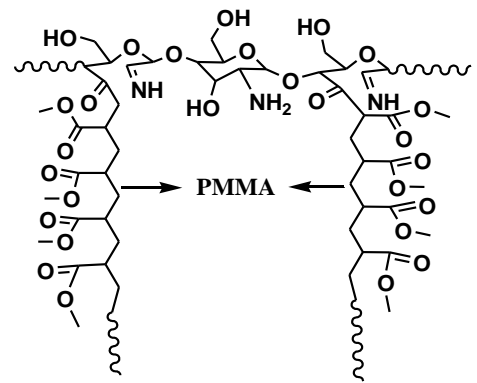

Scheme-1 Structure of Chitosan-g-PMMA

\section{DPPH radical Scavenging Activity}

The potential to suppress the DPPH radical was monitored based on the method of Blois (1958). Chitosan $(0.1 \mathrm{ml})$ was mixed with $0.9 \mathrm{ml}$ of DPPH $(0.041 \mathrm{mM})$ After $60 \mathrm{~min}$ dark incubation, the reduction of the radical intensity was determined at $517 \mathrm{~nm}$. The radical-quenching potential was calculated using the equation:

$\% \operatorname{RSA}=\left[\frac{\left(\mathrm{A}_{\mathrm{DPPH}}-\mathrm{A}_{\mathrm{s}}\right)}{\mathrm{A}_{\mathrm{DPPH}}}\right] \times 100$

\section{Reducing Power}

The reducing power was determined following the method of Oyaizu (1986) Chitosan $(1 \mathrm{ml})$ was mixed with $0.2 \mathrm{M}$ phosphate buffer $(1 \mathrm{ml})$ and potassium ferricyanide $(10 \mathrm{mg} / \mathrm{ml})$ and incubated at $50^{\circ} \mathrm{C} .1 \mathrm{ml}$ of trichloroacetic acid $(100$ $\mathrm{mg} / \mathrm{ml}$ ) was added and centrifuged for $10 \mathrm{~min}$. To the upper layer, $1 \mathrm{ml} \mathrm{of} \mathrm{H}_{2} \mathrm{O}$ and $0.1 \mathrm{ml}$ of $\mathrm{FeCl}_{3}(1.0 \mathrm{mg} / \mathrm{ml})$ was added and the absorbance was read at 700 $\mathrm{nm}$.

\section{$\beta$-carotene bleaching assay}

$\beta$-carotene bleaching assay was carried out based on the method of Matthaus (2002). $\beta$-carotene was dissolved in $1 \mathrm{ml}$ of chloroform. After removing chloroform, $40 \mathrm{mg}$ of linoleic acid, $100 \mathrm{ml}$ of distilled water and Tween 80 emulsifier were added. $0.2 \mathrm{ml}$ of prepared chitosan extracts were added to this mixture and incubated at $50^{\circ} \mathrm{C}$. The zero time absorbance and subsequent absorbance was recorded $(470 \mathrm{~nm})$ at every $30 \mathrm{~min}$ intervals until the control sample had changed colour. Antioxidant potential was measured using the following equation

Antioxidant activity $=\left[\frac{\beta-\text { carotenecontentafter } 120 \text { min of assay }}{\text { Initial } \beta-\text { carotene content }}\right] \times 100$

\section{TBA assay}

Oxidation of lipids was measured by the TBA assay as ascribed by Ruberto and Baratta (1999). $0.05 \mathrm{~g}$ of sample (Penaeus monodon) was mixed with distilled water, $1.5 \mathrm{ml}$ of $20 \%$ acidic acid and $1.5 \mathrm{ml} 0.8 \%$ of TBA in $1.1 \%$ SDS and heated to $100^{\circ} \mathrm{C}$ for $60 \mathrm{~min}$. After cooling, $5 \mathrm{ml}$ butan-1-ol was added. Samples were then centrifuged at $10000 \mathrm{rpm}$ for $15 \mathrm{~min}$. The absorbance of the upper layer was determined spectrophotometrically at $532 \mathrm{~nm}$.

\section{Determination of Total volatile base nitrogen (TVBN)}

Microdiffusion method was employed to analyse total volatile base in Penaeus monodon. Briefly, $1 \mathrm{ml}$ of $\mathrm{H}_{2} \mathrm{SO}_{4}$ was added into the inner chamber of the conway unit along with Tashiro's indicator. In the outer unit of apparatus, $1 \mathrm{ml}$ of $20 \%$ $\mathrm{C}_{2} \mathrm{HCl}_{3} \mathrm{O}_{2}$ extract and $\mathrm{K}_{2} \mathrm{CO}_{3}$ was added. The contents of the inner chamber of unit was titrated against $\mathrm{NaOH}(0.1 \mathrm{~N})$ until a colour change was observed. A blank was carried out with $2 \%$ TCA.

\section{Microbial count in raw Penaeus monodon}

Total viable count was determined in the stored samples from control and all treatment groups. At time 0 and days 5, 10, 15, triplicate samples of each treatment were chosen for total plate count. For microbial analysis, tissue samples (10 gm) was aseptically homogenised using $90 \mathrm{ml}$ of $0.85 \%$ saline, for 1 min and was spread on the surface of plate count agar and incubated at $30^{\circ} \mathrm{C}$ for two days. Microbial load was expressed as $\log \mathrm{CFU} / \mathrm{g}$

\section{Statistical analysis}

One-way analyses of variance were conducted to find out significant differences at $\mathrm{p}<0.05$ using a SPSS package. Experiments were replicated thrice on dissimilar occasions with different fish samples.

\section{RESULTS AND DISCUSSION}

FT-IR spectra of pure chitosan and chitosan-g-PMMA reveal the process of successful grafting (Fig. 1A). In the spectrum of chitosan-g-Poly methyl methacrylate, the distinctive absorption bands around 3421, $1657 \mathrm{~cm}^{-1}$ can be seen. The broad absorption band at $3421 \mathrm{~cm}^{-1}$ denote that $-\mathrm{OH}$ and $-\mathrm{NH}_{2}$ groups are hydrogen bonded and absorption at $1657 \mathrm{~cm}^{-1}$ point out the amide linkage of chitosan backbone with external grafting polymer. In figure 1A (b) the bending frequency of $-\mathrm{NH}_{2}\left(1457 \mathrm{~cm}^{-1}\right)$ and $-\mathrm{OH}\left(1590 \mathrm{~cm}^{-1}\right)$ peaks are shifted approximately by $15 \mathrm{~cm}^{-1}$ compared to the spectra of native chitosan which assures the successful polymerization.
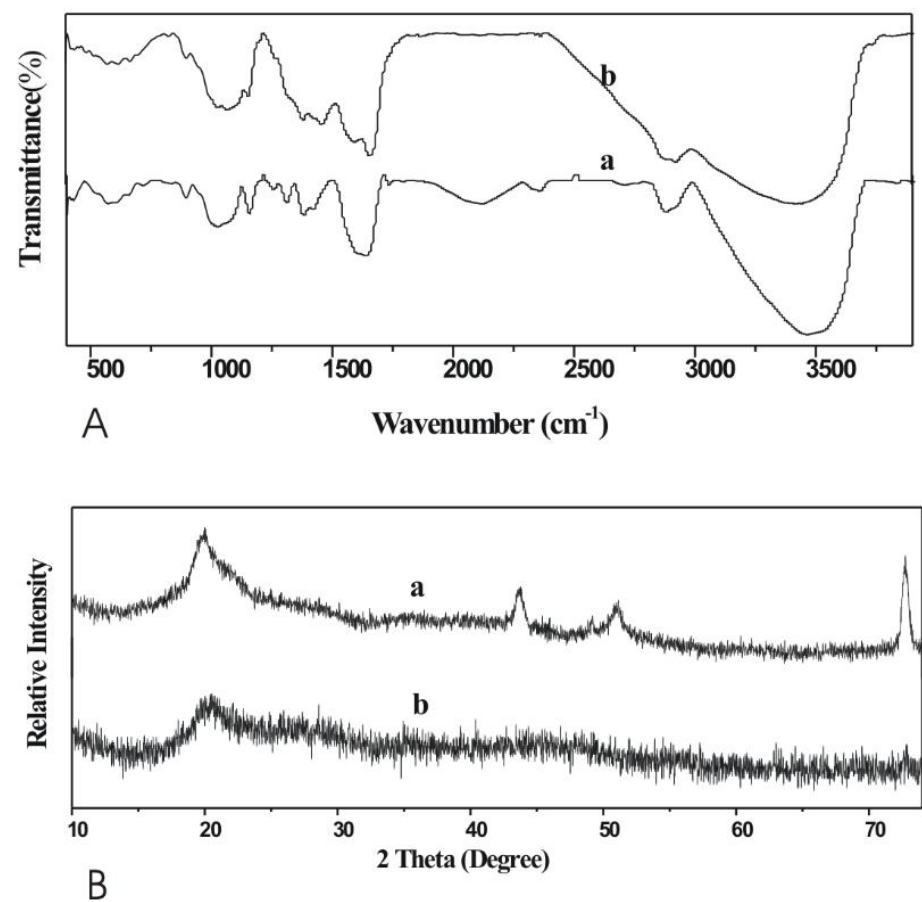

Figure 1 (1A) -FT-IR spectrumof chitosan (a) and chitosan-g-PMMA (b). (1B)XRD spectrum of pure chitosan (a) and chitosan-g-PMMA (b)

The alteration of chitosan structure after polymerization was investigated by powder X-ray diffraction. The powder XRD marks, revealed successful grafting on the chitosan surface. Figure.1B (a, b) depicts the X-ray diffractograms acquired from pure chitosan and chitosan-g-PMMA. Four peaks of pure chitosan with high intensity at $2 \theta=20^{\circ}, 44^{\circ} .52{ }^{\circ}$ and $72^{\circ}$ were observed and the obtained values matches the report of Joshi and Sinha et al. (2002) indicating the crystalline nature of chitosan. Subsequent to polymerization, three peaks on chitosan surface fully disappeared (Figure 1B (b)) which informs the loss of crystallinity in the grafted chitosan. A broad peak at $20^{\circ}$ in grafted chitosan that signify the crystalline structure of chitosan is wholly transformed in to amorphous nature due to the polymerization. In the case of blended chitosan there was noteworthy variation in the intensity of distinctive peaks. The varied differences in the diffraction patterns between chitosan and grafted chitosan could be ascribed due to the adaptation in the arrangement of molecules in the crystal lattice.

Chitosan was observed as homogeneous particles in scanning electron microscopic images. Scanning electron image of native chitosan was used as the reference. The peripheral surfaces of grafts were accumulated in the form of globules as a consequence of the porosity of the graft which are the implications of graft copolymer. The SEM image also showed clustered configuration, 
indicating the connections between chitosan molecules (Figure 2). Following graft copolymerization, irregular rod like and globular shapes were visibly observed.

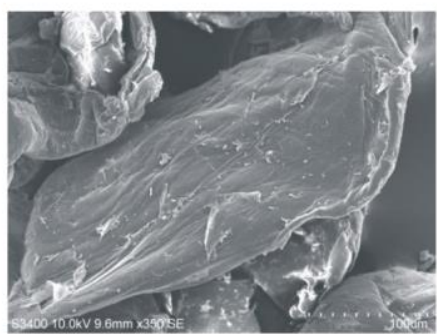

A

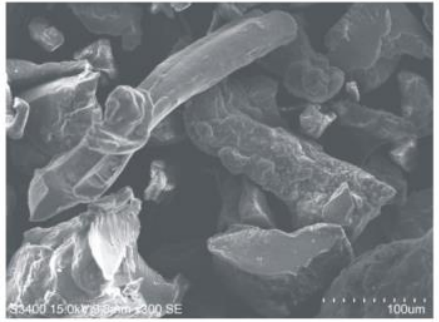

C

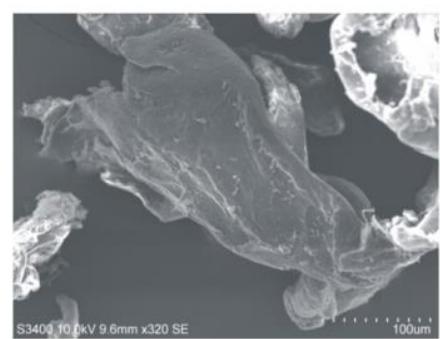

B

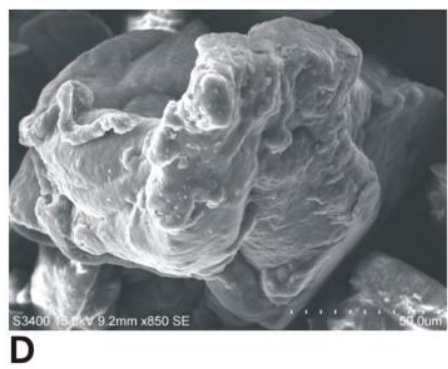

D
Figure 2 SEM image of (A,B) pure chitosan (C,D) chitosan-g-PMMA.

DSC shows the difference in Glass transition temperature (TG) between the pure chitosan and the grafted chitosan (Fig. 3A). Increase in molecular weight due to random polymerization and decline in glacious crystalline nature of grafted chitosan resulted in the decline of glass transition temperature. The blue shift in TG of grafts is due to external graft polymerization. Exothermic peak was found to be decreased in grafts due to increased molecular weight of external polymerization.

The degradation trend and thermal constancy of chitosan and chitosan grafts were evaluated through thermo-gravimetric analysis (TGA) experiments Weight loss in pure chitosan was $54.16 \%$ and starts at $245^{\circ} \mathrm{C}$ whereas weight loss starts at $208^{\circ} \mathrm{C}$ for PMMA grafted chitosan and the total weight loss for PMMA grafted chitosan was $49.63 \%$. Decreased weight loss in case of grafted chitosan compared to native chitosan might be due to the reduction of saccharide units and increased polymerization.

\section{Scavenging activity of modified chitosan:}

Antioxidant activity of the chitosan determined by the bleaching of $\beta$-carotene was presented in fig. 4. Antioxidant activities were $62.33 \pm 3.39 \%, 67.3 \pm 5 \%$, $81.2 \pm 2.34 \%, 87.9 \pm 2.2 \%$, for unmodified chitosan, blended chitosan grafts, $5 \mathrm{kGy}$ irradiated chitosan derivative, $10 \mathrm{kGy}$ irradiated chitosan derivatives respectively. In the presence of customized chitosan, samples retained their colour for a longer time demonstrating the antioxidant potential of modified chitosan. The extent or potential of radical neutralisation varied with different modified chitosans. Modified chitosan reduced the extent of $\beta$-carotene destruction by neutralizing the linoleate free radical formed in the system. The high radical quenching property of chitosan might be due to reaction between the generated free radicals and the residual free amino groups (Tamer et al., 2016).

The antioxidant activity in our study was found to be concomitant with the reducing power of native and modified chitosan samples. The highest reducing power was observed for irradiated chitosan derivatives compared to the unmodified and grafted chitosan. Difference in reducing power was also observed between the groups subjected to irradiation. A higher irradiation dose (10 kGy) exhibited higher radical scavenging activity and higher reducing power compared to chitosan irradiated at $5 \mathrm{kGy}$. The modified chitosan showed higher potential as electron donors to quench free radicals compared to the control (unmodified chitosan). Generally, radical reducing properties are coupled with the endurance of reductones, which split down the radical chain by donating a hydrogen atom (Singh et al., 2002). Reducing powers obtained were in the following order: unmodified chitosan > blended chitosan> $5 \mathrm{kGy}$ irradiated chitosan $>10 \mathrm{kGy}$ irradiated chitosan derivative.
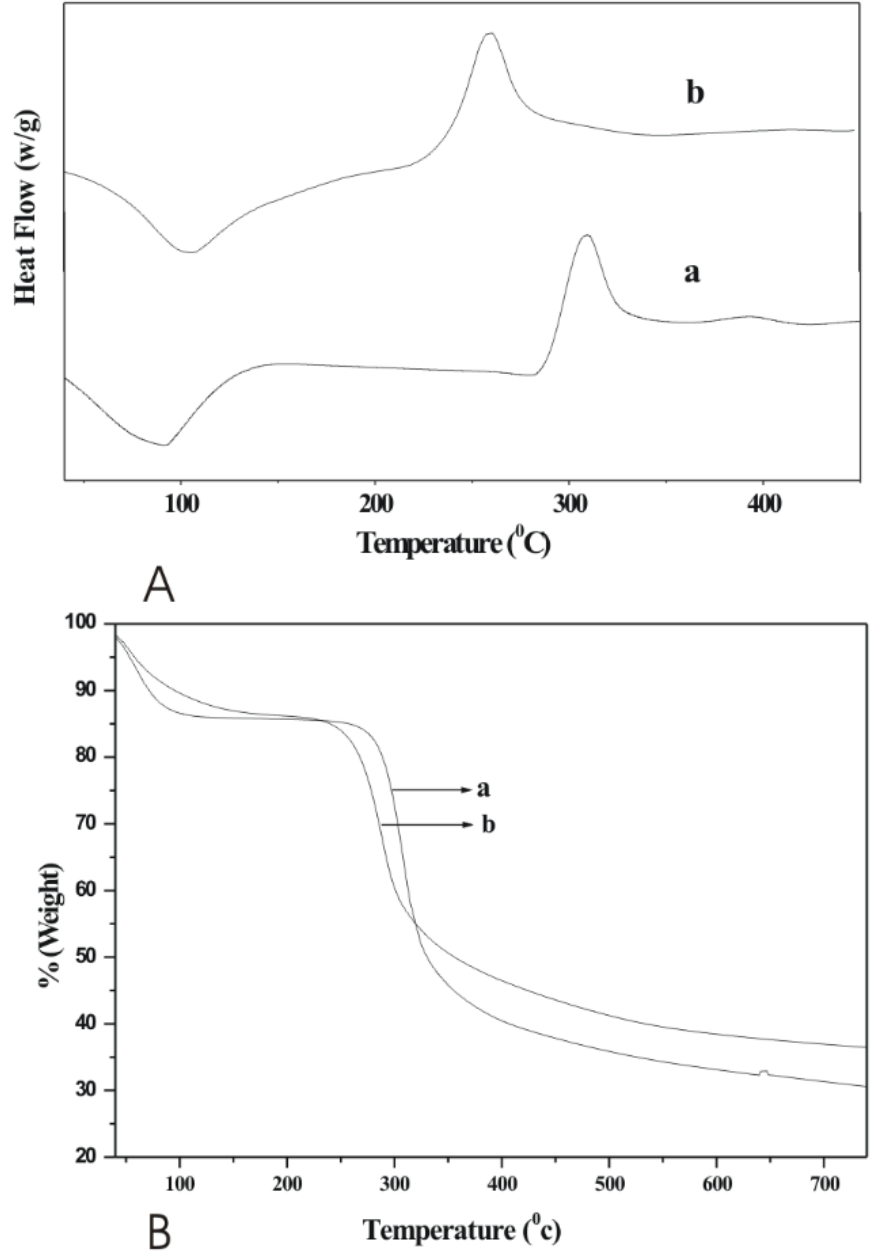

Figure 3 (3A)- DSC of (a) pure chitosan and (b) chitosan-g-PMMA. (3B)Thermal gravimetric analysis (TGA) of (a) pure chitosan (b) chitosan-g-PMMA.

Figure 3B, shows thermograms of (a) pure chitosan and (b) chitosan-g-PMMA respectively. Pure chitosan show evidence of an endothermic peak at temperature around $91.84{ }^{\circ} \mathrm{C}$, which ascribes to the water holding aptitude of chitosan by the $\mathrm{OH}$ and free $-\mathrm{NH}_{2}$ groups. Additionally, chitosan displays an exothermic peak at $304.60{ }^{\circ} \mathrm{C}$ informing decomposition of polysaccharide unit. In the case of figure 3B (b), endothermic peak appear at $101.92{ }^{\circ} \mathrm{C}$ and exothermic peak appear at $284.05{ }^{\circ} \mathrm{C}$ which explores the decreased decomposing peak of chitosan grafted polymer, indicating successful polymerization. Similarly, the glass transition temperature of the chitosan-g-PMMA progressively increased which confirms the decreased crystalline temperament of chitosan due to the grafting.

DPPH assay offers a rapid method for accessing the radical quenching potential. Proton radical scavenging potential was higher in $10 \mathrm{kGy}$ irradiated chitosan derivative $(84 \pm 2.5 \%)$ followed by $5 \mathrm{kGy}$ irradiated chitosan derivative (77.35 $\pm 2.57 \%$ ), blended chitosan (65 \pm 1$)$. Minimal DPPH scavenging activity was observed in unmodified natural chitosan $(63.11 \pm 1.1 \%)$. It is evident from our result, that irradiation of chitosan enhance the antioxidant activity of chitosan. Also the enhancement or increase in antioxidant potential is dose dependent in case of irradiation (Figure 4A).

A similar study carried out by Kannat et al. (2004) revealed that irradiated chitosan exhibited enhanced antioxidant activity than the unirradiated chitosan. In another study carried out by Feng et al. (2008) chitosan irradiated at $20 \mathrm{kGy}$ exhibited higher reductive capacity and better radical scavenging potential. Irradiation treatment has been reported to depolymerise chitosan, thus revealing the free amino groups which increase the DPPH radical quenching activity (Kannat et al. 2004). 

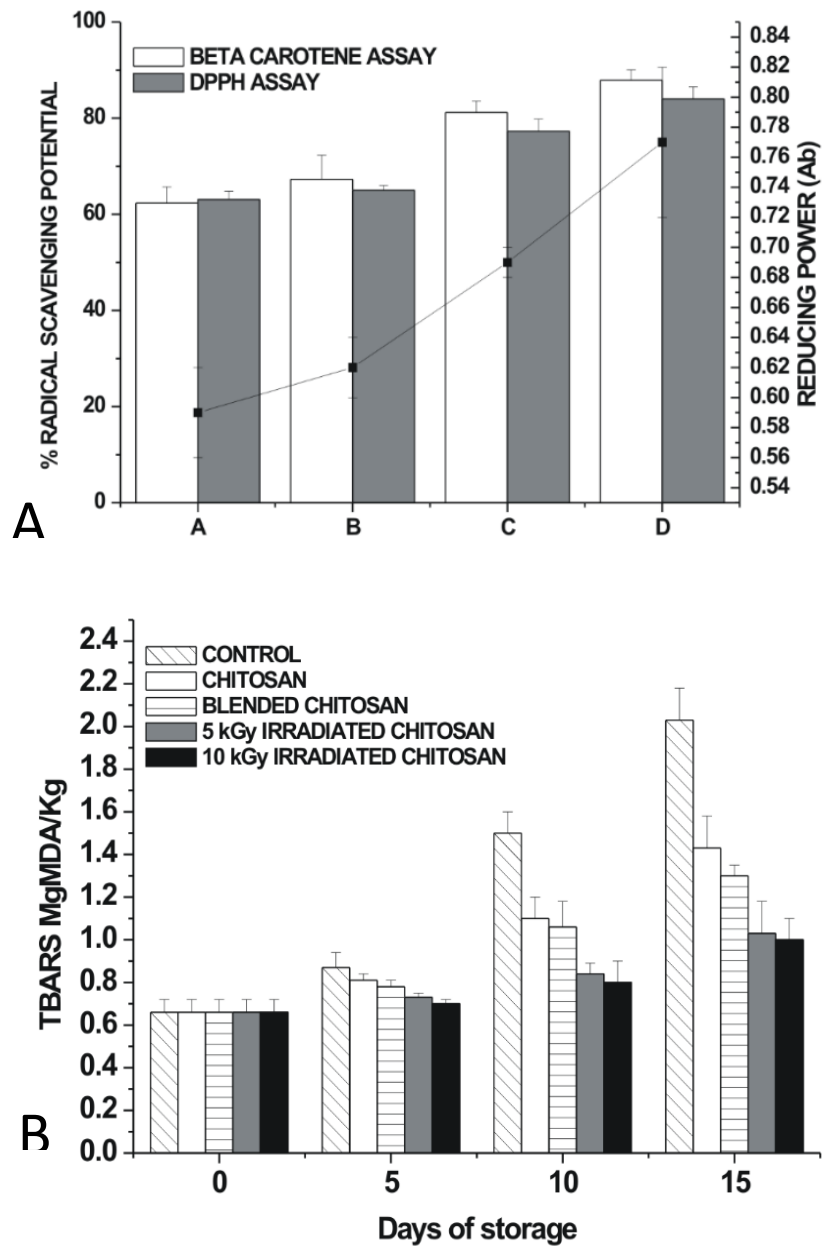

Figure 4A Antioxidant potential of chitosan extracts: A-chitosan. B-Blended chitosan C- $5 \mathrm{kGy}$ irradiated chitosan. D- $10 \mathrm{kGy}$ irradiated chitosan.

4B Evolution of TBARS values in Penaeus monodon (mg MDA Kg${ }^{-1}$ of fish) during refrigerated storage.

\section{Effect of chitosan on t-bars evolution}

This study demonstrated the effectiveness of native and modified chitosan as a natural anti-oxidant, when it was supplemented to the Penaeus monodon Data generated using the TBARS assay in Penaeus monodon during refrigerated storage are presented in Figure 4B. Throughout the study period, Penaeus monodon treated with modified chitosan exhibited lower TBARS values indicative of higher antioxidant activity than the control (no treatment). Though Penaeus monodon treated with unmodified chitosan exhibited antioxidant activity better than control (without chitosan treatment), it was lower than the activity executed by the modified counterparts. The susceptibility of sea food products to endure rancidity mediated disorders during storage is chiefly due to the elevated amounts of unsaturated lipids. By the end of storage time, significant differences $(\mathrm{P}>0.05)$ were observed between the control $(2.03 \pm .15)$ and each of native chitosan, blended chitosan, $5 \mathrm{kGy}, 10 \mathrm{kGy}$ irradiated chitosan infused Penaeus monodon, which exhibited values of $1.43 \pm .15,1.3 \pm .05,1.03 \pm .15,1 \pm .1$ respectively. Throughout the study period, difference in TBARS value was not significant between the unmodified chitosan and blended chitosan but was significant with the samples treated with irradiated chitosan. Similarly, irradiated chitosan exhibited a better anti-oxidant activity in lamb meat than autoclaved chitosan (Kannat et al., 2004). Darmadji and Izumimoto (1994) proposed that the anti-oxidative properties of chitosan are accountable for minimising the TBA values in minced beef.

\section{Total volatile base}

TVB-N contents augmented for all samples during the storage period, with the utmost values recorded for control samples followed by chitosan, blended chitosan, 5 kGy irradiated, 10 kGy irradiated chitosan (Figure 5A).
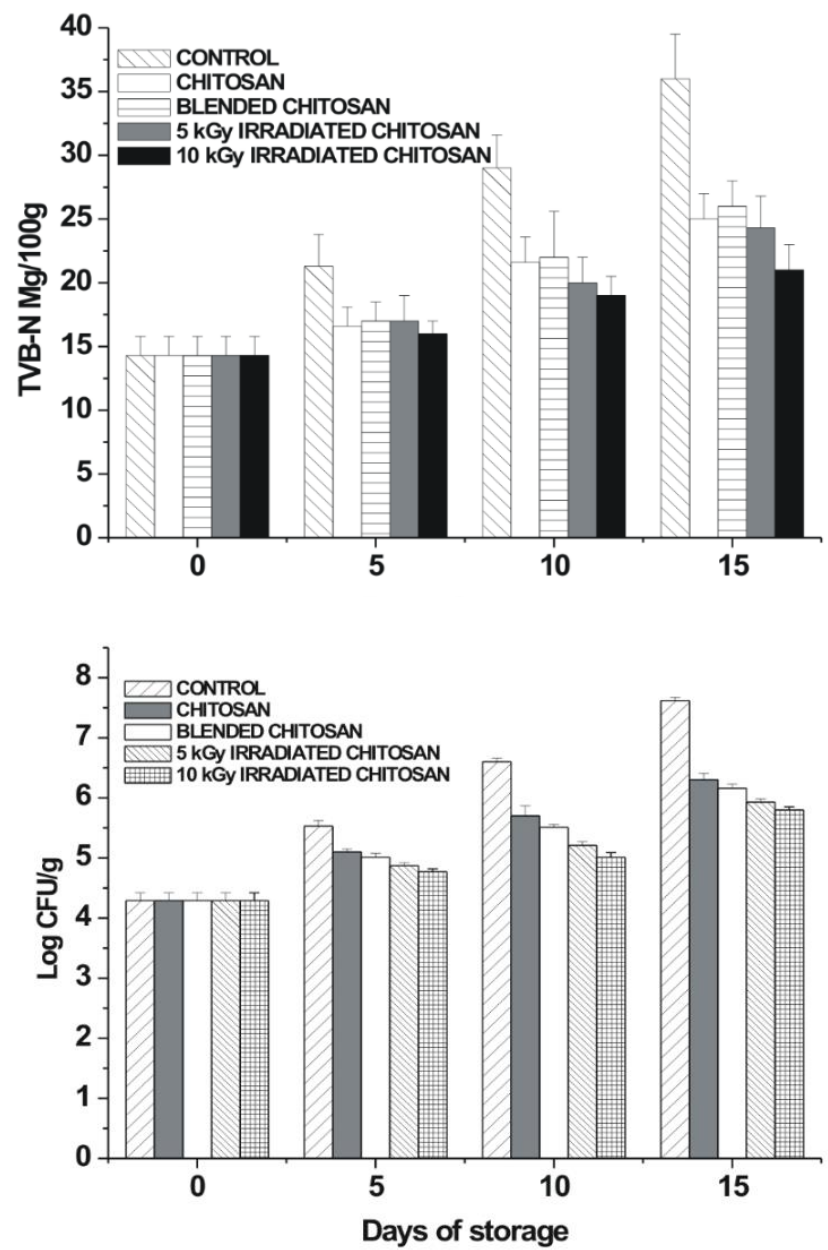

Figure 5A Evolution of TVB values in Penaeus monodon (TVB-N mg/100g) during refrigerated storage.

5B. Profiles of antimicrobial activity in Penaeus monodon treated with chitosan during refrigerated storage.

TVB values also intensified for chitosan treated samples during storage period At the end of storage period, TVB value of control P. monodon was found to be $36 \pm 3.5$ which was higher than chitosan $(26 \pm 2)$, blended chitosan treated $(25 \pm 2), 5$ kGy irradiated chitosan treated (24.3 \pm 2.5$) 10$ kGy chitosan treated (21 \pm 2$)$. No lag phase was detected for control samples during total volatile base generation; a rapid increase in TVB was evident from day-5. Stored control samples surpassed the acceptability margin ( $35 \mathrm{mg}$ TVBN/100 g of fish) set by the European Union for total volatile base values of fish. Though limitation of TVB was not significant between the chitosan treatment groups, all chitosan treated samples, limited the generation of TVB throughout the storage period. A TVB value of 30 $\mathrm{mg}$ which is measured to be spoilage level for human consumption (Harpaz et al., 2003) was attained in control samples by day- 10 whereas none of the chitosan treated groups reached this boundary. Reduction in TVB values by chitosan treatment was reported in fishery products (Jeon et al., 2006; Cao et al., 2009). Reduction of microbial load was evident in chitosan treated samples (Fig. 5B). Chitosan has been reported for its antimicrobial nature due to its polycationic character in various studies (Chen et al., 1998; Shin et al., 2001; Xie et al., 2002). Efficiency of irradiated chitosan on limiting the growth of $E$. coli was studied by Matsuhashi and Kume (1997). Log reduction was high in irradiated chitosan treated samples $(1.5 \mathrm{Log})$ compared to the unmodified chitosan $(1.3 \mathrm{Log})$ treated samples (Figure 5B). Though Log reduction was not significant during early days of storage, marked reduction was noted during later days of storage between the control and treatment groups.

\section{CONCLUSION}

Our research discusses the application of radiation degraded (5 and $10 \mathrm{kGy})$ and grafted chitosan (CH-g-PMMA) for the preservation of sea food Penaeus monodon. Study confirmed that the modified chitosan exhibited better antioxidant and antibacterial potential in the stored Penaeus monodon which is evident from the less TBARS and TVB values and better sensory values Designing a process or material for preserving and processing the sea food plays a crucial role in fulfilling the demands of the food industry. 
Acknowledgement:Authours acknowledge the support received from the centre for research, CHRIST (Deemed to be University).

\section{REFERENCES}

Ali, M., Imran, M., Nadeem, M., Khan, M. K., Sohaib, M., Suleria, H. A. R., \& Bashir, R. (2019). Oxidative stability and sensoric acceptability of functional fish meat product supplemented with plant-based polyphenolic optimal extracts Lipids in Health and Disease, 18(1), 1-16. https://doi.org/:10.1186/s12944-019 0982-y

Blois, M. S. (1958). Antioxidant determinations by the use of a stable free radical. Nature, 181(4617), 1199-1200. https://doi.org/:10.1038/1811199a0

Cao, R., Xue, C. H., \& Liu, Q. (2009). Changes in microbial flora of Pacific oysters (Crassostrea gigas) during refrigerated storage and its shelf-life extension by chitosan. International Journal of Food Microbiology, 131, 272-276. https://doi.org/10.1016/j.ijfoodmicro.2009.03.004

Chen, C.S., Liau, W.Y., \& Tsai, G. J. (1998). Antibacterial Effects of NSulfonated and N-Sulfobenzoyl Chitosan and Application to Oyster Preservation. Journal of Food Protection, 61(9), 1124-1128. https://doi.org/:10.4315/0362 028x-61.9.1124

Chen, L. C., Kung, S. K., Chen, H. H., \& Lin, S. B. (2010). Evaluation of zeta potential difference as an indicator for antibacterial strength of low molecular weight chitosan. Carbohydrate Polymers, 82(3), 913-919. https://doi.org/:10.1016/j.carbpol.2010.06.017

Chen, M. C., Yeh, G. H. C., \& Chiang, B. H. (1996). Antimicrobial and physicochemical properties of methylcellulose and chitosan films containing a preservative. Journal of Food Processing and Preservation, 20(5), 379-390. https://doi.org/:10.1111/j.1745-4549.1996.tb00754.x

Czechowska-Biskup, R., Rokita, B., Ulanski, P., \& Rosiak, J. M. (2005) Radiation-induced and sonochemical degradation of chitosan as a way to increase its fat-binding capacity. Nuclear Instruments and Methods in Physics Research Section B: Beam Interactions with Materials and Atoms, 236(4), 383-390. https://doi.org/:10.1016/j.nimb.2005.04.002

Darmadji, P., \& Izumimoto, M. (1994).Effect of chitosan in meat preservation. Meat Science, 38(2), 243-254. https://doi.org/:10.1016/0309-1740(94)90114-7 Don, T. M., King, C. F., \& Chiu, W. Y. (2002).Synthesis and properties of chitosan-modified polyvinyl acetate. Journal of Applied Polymer Science, 86(12), 3057-3063. https://doi.org/:10.1002/app.11329

El-Tahlawy, K. F., El-Rafie, S. M., \& Aly, A. S. (2006). Preparation and application of chitosan/polymethacrylic acid graft copolymer. Carbohydrate Polymers, 66(2), 176-183. https://doi.org/:10.1016/j.carbpol.2006.03.001

Fan, W., Sun, J., Chen, Y., Qiu, J., Zhang, Y., \& Chi, Y. (2009). Effects of chitosan coating on quality and shelf life of silver carp during frozen storage Food Chemistry, 115(1), 66-70. https://doi.org/:10.1016/i.foodchem.2008.11.060 Fang, Y., Lou, M., Li, B., Xie, G. L., Wang, F., Zhang, L. X., \& Luo, Y. C. (2009). Characterization of Burkholderia cepacia complex from cystic fibrosis patients in China and their chitosan susceptibility. World Journal of Microbiology and Biotechnology, 26(3), 443-450 https://doi.org/:10.1007/s11274-009-0187-Z

Feng, T., Du, Y., Li, J., Hu, Y., \& Kennedy, J. F. (2008). Enhancement of antioxidant activity of chitosan by irradiation. Carbohydrate Polymers, 73(1), 126-132. https://doi.org/:10.1016/j.carbpol.2007.11.00

Harish Prashanth, K. V., \& Tharanathan, R. N. (2007). Chitin/chitosan: modifications and their unlimited application potential-an overview. Trends in Food Science \& Technology, 18(3), 117-131. https://doi.org/:10.1016/j.tifs.2006.10.02

Harpaz, S., Glatman, L., Drabkin, V., \& Gelman, A. (2003). Effects of herbal essential oils used to extend the shelf life of freshwater-reared Asian sea bass fish (Lates calcarifer). Journal of Food Protection, 66(3), 410-417. https://doi.org/:10.4315/0362-028x-66.3.410

Jeon, Y. J., Kamil, J. Y. V. A., \& Shahidi, F. (2002). Chitosan as an edible invisible film for quality preservation of herring and atlantic cod. Journal of Agricultural and Food Chemistry, 50(18), 5167-5178. https://doi.org/:10.1021/jf011693

Joshi, J. M., \& Sinha, V. K. (2006). Synthesis and characterization of carboxymethyl chitosan grafted methacrylic acid initiated by ceric ammonium nitrate. Journal of Polymer Research, 13(5), 387-395. https://doi.org/:10.1007/s10965-006-9056-8

Kanatt, S. R., Chander, R., \& Sharma, A. (2004). Effect of irradiated chitosan on the rancidity of radiation-processed lamb meat. International Journal of Food Science and Technology, 39(9), 997-1003. https://doi.org/:10.1111/j.13652621.2004.00868.x

Kim, K. W., \& Thomas, R. L. (2007). Antioxidative activity of chitosans with varying molecular weights. Food Chemistry, 101(1), 308-313. https://doi.org/10.1016/j.foodchem.2006.01.038

Kume, T., Nagasawa, N., \& Yoshii, F. (2002). Utilization of carbohydrates by radiation processing. Radiation Physics and Chemistry, 63(3-6), 625-627. https://doi.org/10.1016/s0969-806x(01)00558-8
López-Caballero, M. E., Gómez-Guillén, M. C., Pérez-Mateos, M., \& Montero, P. (2005). A chitosan-gelatin blend as a coating for fish patties. Food Hydrocolloids, 19(2), 303-311. https://doi.org/10.1016/j.foodhyd.2004.06.006 Mahdavinia, G. R., Zohuriaan-Mehr, M. J., \& Pourjavadi, A. (2004). Modified chitosan III, superabsorbency, salt- and $\mathrm{pH}$-sensitivity of smart ampholytic hydrogels from chitosan-g-PAN. Polymers for Advanced Technologies, 15(4) 173-180. https://doi.org/10.1002/pat.408

Ravi Kumar, M. N. (2000). A review of chitin and chitosan applications. Reactive and Functional Polymers, 46(1), 1-27. https://doi.org/10.1016/s1381 5148(00)00038-9

Matsuhashi, S., \& Kume, T. (1997). Enhancement of antimicrobial activity of chitosan by irradiation. Journal of the Science of Food and Agriculture, 73(2), 237-241. https://doi.org/: 10.1002/(sici)1097-0010(199702)73:2<237::aidjsfa711>3.0.co;2-4

Matthäus, B. (2002). Antioxidant activity of extracts obtained from residues of different oilseeds. Journal of Agricultural and Food Chemistry, 50(12), 3444 3452. https://doi.org/:10.1021/jf011440s

Oyaizu, M. (1986). Studies on products of browning reaction. Antioxidative activities of products of browning reaction prepared from glucosamine. The Japanese Journal of Nutrition and Dietetics, 44(6), 307-315. https://doi.org/:10.5264/eiyogakuzashi.44.307

Park, P. J., Je, J. Y., \& Kim, S. K. (2004). Free radical scavenging activities of differently deacetylated chitosans using an ESR spectrometer. Carbohydrate Polymers, 55(1), 17-22. https://doi.org/:10.1016/j.carbpol.2003.05.002

Pourjavadi, A., Mahdavinia, G. R., \& Zohuriaan-Mehr, M. J. (2003). Modified chitosan. II. H-chitoPAN, a novel pH-responsive superabsorbent hydrogel. Journal of Applied Polymer Science, 90(11), 3115-3121. https://doi.org/:10.1002/app.13054

Rong, C., Qi, L., Bang-zhong, Y., \& Lan-lan Zhu. (2010). Combined effect of ozonated water and chitosan on the shelf-life of pacific oyster (Crassostrea gigas). Innovative Food Science \& Emerging Technologies, 11(1), 108-112. https://doi.org/:10.1016/j.ifset.2009.08.006

Raafat, D., \& Sahl, H. G. (2009). Chitosan and its antimicrobial potential - a critical literature survey. Microbial Biotechnology, 2(2), 186-201. https://doi.org/:10.1111/j.1751-7915.2008.00080.x

Radhakumary, C., Nair, P. D., Reghunadhan Nair, C. P., \& Mathew, S. (2012). Chitosan-graft-polyvinyl acetate for hemodialysis applications. Journal of Applied Polymer Science, 125(3), 2022-2033. https://doi.org/:10.1002/app.36261 Rhoades, J., \& Roller, S. (2000). Antimicrobial actions of degraded and native chitosan against spoilage organisms in laboratory media and foods. Applied and Environmental Microbiology, 66(1), 80-86. https://doi.org/:10.1128/aem.66.1.80$\underline{86.2000}$

Ruberto, G., \& Baratta, M. T. (2000). Antioxidant activity of selected essential oil components in two lipid model systems. Food Chemistry, 69(2), 167-174 https://doi.org/:10.1016/s0308-81469900247-2

Shin, Y., Yoo, D. I., \& Jang, J. (2001). Molecular weight effect on antimicrobia activity of chitosan treated cotton fabrics. Journal of Applied Polymer Science, 80(13), 2495-2501. https://doi.org/:10.1002/app.1357

Singh, R. P., Chidambara Murthy, K. N., \& Jayaprakasha, G. K. (2002). Studies on the antioxidant Activity of pomegranate (Punica granatum) peel and seed extracts using in vitro models. Journal of Agricultural and Food Chemistry, 50(1), 81-86. https://doi.org/:10.1021/jf010865b

Song, Z., Li, G., Guan, F., Liu, W. (2018). Application of chitin/chitosan and their derivatives in the papermaking industry. Polymers, 10(4), 389. https://doi.org/: 10.3390/polym10040389

Song, Y., Babiker, E. E., Usui, M., Saito, A., \& Kato, A. (2002). Emulsifying properties and bactericidal action of chitosan-lysozyme conjugates. Food Research International, 35(5), 459-466. https://doi.org/:10.1016/s096399690100144-2

Suyatma, N. E., Copinet, A., Tighzert, L., \& Coma, V. (2004). Mechanical and barrier properties of biodegradable films made from chitosan and polyLactic acid blends. Journal of Polymers and the Environment, 12(1), 1-6. https://doi.org/:10.1023/b:jooe.0000003121.12800.4e

Tamer, T., Aacute,, K., Mohyeldin, M., \& Soltes, L. (2016). Free radical scavenger activity of chitosan and its aminated derivative. Journal of Applied Pharmaceutical Science, 195-201. https://doi.org/:10.7324/japs.2016.60428

Tepe, B., Sokmen, M., Akpulat, H. A., Daferera, D., Polissiou, M., \& Sokmen, A. (2005). Antioxidative activity of the essential oils of Thymus sipyleus subsp. sipyleus var. sipyleus and Thymus sipyleus subsp. sipyleus var. rosulans. Journal of Food Engineering, 66(4), 447-454 https://doi.org/:10.1016/j.jfoodeng.2004.04.015

Xie, W. (2002). Preparation and antibacterial activity of a water-soluble chitosan derivative. Carbohydrate Polymers, 50(1), 35-40. https://doi.org/:10.1016/s0144$\underline{86170100370-8}$ 